\title{
Stock Price Dynamics and the Business Cycle in an Estimated DSGE Model for South Africa
}

\author{
Michael Paetz* \\ University of Hamburg \\ Rangan Gupta ${ }^{\dagger}$ \\ University of Pretoria
}

August 19, 2014

\begin{abstract}
This paper develops and estimates an open economy dynamic stochastic general equilibrium model of South Africa. We devote special attention to the impact of stock price wealth effects on output and the interest rate. For this reason we adopt a perpetual youth approach, which allows for a limited decision horizon. We estimate the model using Bayesian techniques and find that (i) about 9 percent of the volatility in production can be explained by financial shocks, and (ii) the SARB does not and should not react on stock price disturbances. Moreover, stock prices seem to be unaffected by shocks from the real economy.
\end{abstract}

Keywords: DSGE models, wealth effects, open economy, South Africa.

JEL classification: D91, E21, E44, F41.

*email: michael.paetz@wiso.uni-hamburg.de

†email: Rangan.Gupta@up.ac.za 


\section{Contents}

Contents i

1 Introduction 1

2 The DSGE Framework 2

2.1 Households Optimal Intertemporal Allocation . . . . . . . . . . . . 3

2.2 Equilibrium and Log-Linearisation . . . . . . . . . . . . . . . . . . 6

2.3 The Canonical Representation . . . . . . . . . . . . . . . . . . . 8

3 Estimation and Model Fit 9

4 Conclusions 17

$\begin{array}{ll}\text { A Appendix } & 18\end{array}$

A.1 About the Model . . . . . . . . . . . . . . . . . . . . . . . . 18

A.1.1 Firms . . . . . . . . . . . . . . . . . 18

A.1.2 Households . . . . . . . . . . . . . . . . . 20

A.1.3 International Risk Sharing and the UIP . . . . . . . . . . . . 22

A.1.4 Deriving Price and Wage Inflation . . . . . . . . . . . . 23

A.2 About the Estimation . . . . . . . . . . . . . . . . . . . 25

$\begin{array}{ll}\text { References } & 25\end{array}$ 


\section{Introduction}

Though there exists a vast and comprehensive literature on South African business cycles (see Burger (2010) for a detailed literature review), only a few studies relate real economic activity with stock prices dynamics. Notable exceptions are Moolman (2004), Moolman and Jordaan (2005), Odhiambo (2010), Bonga-Bonga (2011, 2012), and Muroyiwa (2011). All these studies rely on variations of vector autoregressive (VAR) or vector error-correction (VEC) frameworks, which are primarily a-theoretical in nature. These type of models involve only a few variables and therefore tend to be misspecified. As a consequence, the results from these studies could be biased and probably differ from the true magnitude of stock price wealth effects on output. Further, these approaches are a-theoretical and nonstructural, and hence suffer from the Lucas (1976) critique. ${ }^{1}$

The lack of studies analysing the impact of stock prices on the South African business cycle through the use of an estimated theoretical framework is quite baffling. Financial wealth accounts for 49.95 percent of household's total assets and 61.59 percent of households net worth (see Aye et al. (forthcoming)). Using a theoretical framework could help understanding the wealth channel, quantify its importance, and might also provide recommendations for policy-makers. Our study tries to shed light on this channel, which seems to be accountable for a South African recession for over 9 months covering the last quarter of 2008 till the second quarter of 2009. The objective is to evaluate the impact of stock market spillovers on the South African business cycle using a small-open economy new Keynesian dynamic stochastic general equilibrium model (SOE-NKDSGE).

Studying the effect of wealth on consumption dynamics has a long history in economics. While most textbook IS-LM type models ignore this effect and postulate consumption to depend solely on disposable income, extensions like for example the Blinder and Solow (1973) model include personal wealth, which can be accumulated by buying government bonds or holding money. However, modern business cycle models are based on infinitely living utility maximizers with rational expectations. These so-called Ricardians smooth their consumption path according to an Euler equation. Given their subjective discount factor, which represents their personal degree of patience, consumption dynamics depend on nothing but the opportunity cost of consumption: the interest rate. Wealth effects are excluded by assumption, since the infinite time horizon eliminates temporary ups and downs in personal wealth on average. In contrast, the recently developed perpetual youth approach with a limited decision horizon allows temporary increases in stock price wealth to affect consumption.

Studying the effect of stock price dynamics on the business cycle could also

\footnotetext{
${ }^{1}$ Studies with a focus on broader wealth effects upon consumption (housing, oil, etc.) are, for example, Das et al. (2011), Aron and Muellbauer (2013), Aye et al. (2013, forthcoming) and Apergis et al. (2014). All these studies indicate that stock prices have significant spillover effects on consumption.
} 
offer important information for central banks. Besides the fact that stock market spillovers could be inflationary if they significantly affect aggregate demand through consumption, the recent financial crisis has rekindled the debate on whether central banks should conduct monetary policy in a more active manner to prevent the development of bubbles that can be costly in terms of future output and financial stability (André et al. (2012)). To the best of our knowledge, there are only three papers, that investigate the behaviour of the interest rate in response to stock price movements in South Africa, namely that of Bonga-Bonga (2011), Muroyiwa (2011) and Aye et al. (forthcoming). These studies suggest that the South African Reserve Bank (SARB) responds significantly to stock price movements. ${ }^{2}$ While our Bayesian estimates below suggest, that financial shocks explain up to 9 percent of the volatility in production, we do not find a significant reaction of the SARB on stock price misalignments. Moreover, we find that a strong reaction of the monetary authority would have increased the business cycle volatility, since a dampening effect on stock prices can only be achieved at very high cost in terms of lower real activity and higher unemployment.

The reminder of the paper is organized as follows: Section 2 develops a perpetual youth DSGE model, which will be estimated and analysed in section 3 . The final section concludes.

\section{The DSGE Framework}

Our framework is mainly based on the work of Castelnuovo and Nisticó (2010) on wealth effects in the US and the seminal work of Galí and Monacelli (2005) on small open economy models. A similar combination can be found in Funke et al. (2011), who find substantial stock price wealth effects for Hong Kong. In order to capture the influence of stock prices on consumption, the conventional open economy DSGE framework is reformulated so that the Euler equation for consumption accounts for stock price dynamics.

The economy is inhabited by households and firms. Each household is specialised in one specific type of labour $l \in[0,1]$, is endowed with some monopoly power, and chooses the wage at which it is willing to work in a staggered manner. Each cohort $j$ spans the entire continuum of labour varieties. Firms face the conventional New Keynesian optimization problems based on a competitive goods market (drawn from Dixit and Stiglitz (1977)) and sticky price set-up (drawn from Calvo (1983)). ${ }^{3}$ In a two-stage production, final goods producers use differentiated goods $k \in[0,1]$ from the continuum of intermediate goods producers (wholesale sector) as input. Final goods producers are assumed to produce

\footnotetext{
${ }^{2}$ According to Pariés and Notarpietro (2008) and Finocchiaro and Heideken (2013) these nonmicrofounded studies are likely to produce biased and dispersed estimates.

${ }^{3}$ We follow the empirical literature and allow for additional backward-looking elements by assuming that a fraction of backward-looking price-setters exists.
} 
competitively using a CES technology, consisting of a continuum of nontraded intermediate goods.

We further assume that intermediate firms issue equity shares. Consequently, households can hold two types of financial assets: state-contingent bonds and equity shares of intermediate firms. Since bonds are traded internationally, nominal gross returns on internationally tradable state-contingent bonds are equalized across countries (international risk-sharing), and the Uncovered Interest Parity (UIP) holds. Furthermore, the Law of One Price (LOOP) holds at the brand level, implying Purchasing Power Parity (PPP) at any point in time.

As we define the domestic economy as one among a continuum of infinitesimally small economies, it is of negligible size relative to the rest of the world. Since we focus on the interaction of one economy with the rest of the world, we call this the domestic country and do not use an $i$-index for variables from this country. Instead, variables with an index $i \in[0,1]$ refer to one economy $i$ among the continuum making up the rest of the world. The superscript $*$ here refers to all foreign countries (the rest of the world as a whole).

In what follows, we describe the microfoundations of foreign countries only where we see necessary. Otherwise, the foreign country counterparts of domestic equations can be derived in a straightforward manner. If not explicitly mentioned, price indices are measured in domestic currency units. For the sake of readability, we focus on those the modifications of a standard SOE-NKDSGE needed to allow for stock price wealth effects. Therefore, the optimization problems of domestic firms in the retail and wholesale sectors, the intratemporal allocation and the optimal wage setting scheme, as well as the risk-sharing of households via the trading of bonds on complete security markets are derived in the appendix.

\subsection{Households Optimal Intertemporal Allocation}

Following Blanchard (1985), each economy consists of an indefinite number of cohorts facing a constant probability $\xi$ of dying each period. The implied expected lifetime of $1 / \xi$ can be interpreted as the effective decision horizon of consumers. As in conventional DSGE models, households demand consumption goods and supply labor. Each cohort $j$ is allowed to buy two types of financial assets. The first type are domestic and foreign state-contingent bonds, which holdings of a cohort $j$, specialised in labour type $l$, are denoted by $B_{t}(j, l)$ for domestic bonds and $B_{t}^{i}(j, l)$ for bonds from country $i$. The second type are equity shares of domestic intermediate firms (denoted by a subscript $k$ ), for which nominal prices are given by $Q_{t}(k){ }^{4}$

\footnotetext{
${ }^{4}$ We exclude the possibility of cohort members buying foreign shares. Since stock markets all over the world are highly correlated, introducing a foreign stock market into this study would likely add little insight at probably high costs in terms of modelling and estimation. In addition, our focus lies clearly on the impact of the domestic stock market dynamics.
} 
Before describing the decision problems of households, we briefly clarify our notation. $Z_{t}(k, j, l)$ is defined as the equity shares of a firm $k$ held by the cohort $j$ of labour type $l$. The corresponding nominal composite dividend yield is given by $D_{t}(k)$. Following this notation, the nominal financial wealth of a domestic individual of cohort $j$ is given by

$$
\Omega_{t}(j, l) \equiv \frac{1}{1-\xi}\left[\begin{array}{c}
B_{t}(j, l)+\int_{0}^{1} \mathcal{E}_{t}^{i} B_{t}^{i}(j, l) d i \\
+\int_{0}^{1}\left(Q_{t}(k)+D_{t}(k)\right) Z_{t}(k, j, l) d k
\end{array}\right],
$$

where $\mathcal{E}_{t}^{i}$ is the nominal bilateral exchange rate (defined as the domestic price of country $i$ 's currency). Following (1), financial wealth includes bond holdings and the pay-off on the portfolio of equity shares (dividends plus market value). Since financial wealth also pays off the gross return on the insurance contract, redistributing among surviving consumers, total personal financial wealth is accrued by $\frac{1}{1-\xi} \cdot 5$

A domestic representative household of cohort $j$ and labour type $l$ seeks to maximize his additively separable utility conditional on survival,

$$
E_{0}\left[\sum_{t=0}^{\infty} \beta^{t}(1-\xi)^{t}\left[\mathcal{V}_{t} \log C_{t}(j, l)+\log \left(1-N_{t}(j, l)\right)\right]\right],
$$

subject to a sequence of dynamic budget constraints (in real terms)

$$
\begin{aligned}
& C_{t}(j, l)+\frac{1}{P_{t}} E_{t}\left\{F_{t, t+1} B_{t+1}(j, l)\right\}+\int_{0}^{1} \frac{\mathcal{E}_{t}^{i}}{P_{t}} E_{t}\left\{F_{t, t+1} B_{t+1}^{i}(j, l)\right\} d i \\
& +\frac{1}{P_{t}} \int_{0}^{1} Q_{t}(k) Z_{t+1}(k, j, l) d k=\frac{W_{t}(l)}{P_{t}} N_{t}(j, l)-T_{t}(j, l)+\frac{\Omega_{t}(j, l)}{P_{t}},
\end{aligned}
$$

where $C_{t}(j, l), N_{t}(j, l), W_{t}(l)$ and $P_{t}$ represent consumption, labour supply, the wage rate and the consumption price index $(\mathrm{CPI})$, respectively, $F_{t, t+1}$ is the relevant discount factor for state-contingent claims, $T_{t}$ are real government transfers, and $\beta$ is the discount factor of the representative agent. ${ }^{6}$ We also add a preference shock $\mathcal{V}_{t} \equiv \exp \left(\nu_{t}\right)$, reflecting shifts in the marginal utility of consumption.

Domestic human wealth is defined as discounted stream of expected nontradable income conditional on survival:

$$
H_{t}(j, l) \equiv E_{t}\left\{\sum_{k=0}^{\infty} F_{t, t+k}(1-\xi)^{k}\left(\frac{W_{t}(l)}{P_{t}} N_{t}(j, l)-T_{t}(j, l)\right)\right\} .
$$

In equilibrium, the necessary first-order conditions associated with this utility max-

\footnotetext{
${ }^{5}$ See Blanchard (1985) for details.

${ }^{6}$ Many empirical papers allow for consumption habits to capture the persistence in consumption dynamics. Since the estimated habits, included in an early version of this paper, were small and only had a minor influence on our estimates, we decided to reformulate the model without habits. A draft of the extended model is available upon request.
} 
imization problem may be stated as (2) and

$$
\begin{aligned}
F_{t, t+1} & =\beta E_{t}\left[\left(\frac{P_{t}}{P_{t+1}}\right)\left(\frac{C_{t}(j, l)}{C_{t+1}(j, l)}\right)\right] \exp \left(\Delta E_{t} \nu_{t+1}\right), \\
Q_{t}(k) & =E_{t}\left\{F_{t, t+1}\left[Q_{t+1}(k)+D_{t+1}(k)\right]\right\} .
\end{aligned}
$$

As in conventional DSGE models, (4) is the well-known consumption Euler equation, describing the optimal intertemporal consumption pattern (the equilibrium stochastic discount factor for one-period ahead nominal payoffs equals the timediscounted stochastic growth in the marginal utility of consumption). In addition, (5) is the optimal inter-temporal decision concerning the holdings of equity shares and equates the nominal price of a portfolio to its nominal expected payoff one period ahead, discounted by $F_{t, t+1}$. This equation represents a stock price Euler equation and describes its dynamic pattern. ${ }^{7}$

By combining the Euler equation with a No-Ponzi-Game condition and the definition of human wealth, we can derive consumption as linear function of financial and human wealth:

$$
C_{t}(j, l)=\frac{1}{\Sigma_{t}}\left(\frac{\Omega_{t}(j, l)}{P_{t}}+H_{t}(j, l)\right)
$$

where $\Sigma_{t} \equiv E_{t}\left\{\sum_{i=0}^{\infty} \beta^{i}(1-\xi)^{i} \exp \left(\nu_{t+k}-\nu_{t}\right)\right\}$ is the reciprocal of the time-varying propensity to consume out of financial and human wealth.

Aggregation Across Cohorts and Labour-types After aggregating across cohorts and labour-types, the intratemporal conditions are given by

$$
C_{H, t}=(1-\alpha)\left(\frac{P_{H, t}}{P_{t}}\right)^{-\varpi} C_{t}, C_{F, t}=\alpha\left(\frac{P_{F, t}}{P_{t}}\right)^{-\varpi} C_{t}, C_{i, t}=\left(\frac{P_{i, t}}{P_{F, t}}\right)^{-\zeta} C_{F, t},
$$

and

$$
C_{t} \equiv\left[(1-\alpha)^{\frac{1}{\omega}}\left(C_{H, t}\right)^{\frac{\omega-1}{\omega}}+\alpha^{\frac{1}{\varpi}}\left(C_{F, t}\right)^{\frac{\omega-1}{\varpi}}\right]^{\frac{\varpi}{\varpi-1}} .
$$

Since all equilibrium conditions are linear in cohort-specific variables, the aggregate conditions are simply given by

$$
\begin{aligned}
P_{t} C_{t}+E_{t}\left\{F_{t, t+1} \Omega_{t+1}\right\} & =W_{t} N_{t}-P_{t} T_{t}+\Omega_{t}, \\
Q_{t}(k) & =E_{t}\left\{F_{t, t+1}\left[Q_{t+1}(k)+D_{t+1}(k)\right]\right\}, \\
C_{t} & =\frac{1}{\Sigma_{t}}\left(\frac{\Omega_{t}}{P_{t}}+H_{t}\right),
\end{aligned}
$$

\footnotetext{
${ }^{7}$ The optimal labour-leisure decision (depending on the real wage) is made by the unions and shown in the appendix.
} 
with aggregate nominal financial wealth given by

$$
\Omega_{t} \equiv B_{t}+\int_{0}^{1} \mathcal{E}_{t}^{i} B_{t}^{i} d i+\int_{0}^{1}\left(Q_{t}(k)+D_{t}(k)\right) Z_{t}(k) d k .
$$

From the first-order conditions we can derive the optimal consumption dynamics. Combining (7) and (8) yields the patterns of aggregate consumption, where the effect of financial wealth fades out as the probability of exiting the market goes to zero:

$$
\left(\Sigma_{t}-1\right) P_{t} C_{t}=\xi E_{t}\left\{F_{t, t+1} \frac{\Omega_{t+1}}{P_{t}}\right\}+(1-\xi) E_{t}\left\{F_{t, t+1} P_{t+1} \Sigma_{t+1} C_{t+1}\right\} .
$$

\subsection{Equilibrium and Log-Linearisation}

As the model can be solved for an infinite number of steady states, we restrict the initial equilibrium and assume (without loss of generality) a baseline symmetric steady state with equal and constant consumption and a real exchange rate of value one. Together with PPP, this also implies a value of one for the terms of trade. In what follows, lower-case letters are used for describing percentage deviations from equilibrium values of their upper-case counterparts. ${ }^{8}$

The Government and Market Clearing Following Galí (2003) the government purchases a time-varying fraction $\iota_{t}$ of output of each good, financed by lump-sum taxation. Consequently, goods market clearing for each good $k$ of the domestic small open economy requires

$$
\left(1-\iota_{t}\right) Y_{t}(k)=C_{H, t}(k)+\int_{0}^{1} C_{H, t}^{i}(k) d i
$$

for all $k \in[0,1]$ and all $t$, where $C_{H, t}^{i}(k)$ represents country i's demand for the domestic good $k$. Defining a government expenditure shock $g_{t}$ implicitly by $\exp \left(-g_{t}\right) \equiv$ $\log \left(1-\iota_{t}\right)$, we derive the following approximation around a symmetric steady state

$$
y_{t}=(1-\alpha) c_{t}+\alpha y_{t}^{*}+\alpha \vartheta s_{t}+g_{t},
$$

where $\vartheta=\zeta+(1-\alpha)(\varpi-1)$ and $s_{t}=p_{F, t}-p_{H, t}$ represents the terms-of-trade.

Output, Stocks, and Dividends The indices of average real dividend payments and the average stock market capitalization are

$$
D_{t} \equiv \frac{1}{P_{t}} \int_{0}^{1} D_{t}(k) d k, Q_{t} \equiv \frac{1}{P_{t}} \int_{0}^{1} Q_{t}(k) d k .
$$

\footnotetext{
${ }^{8}$ To clarify the notation: $P_{H, t}$ is the price index for domestic products and $P_{F, t}$ is the price index for imported goods. See the appendix or Galí and Monacelli (2005) for details.
} 
The assumption of a balanced world government budget only requires that the equilibrium aggregate world net supply of state-contingent bonds must equal zero. However, we can approximate around any given distribution of bonds across countries, and thus assume that bond holdings of domestic and foreign households are zero in the initial equilibrium: $B_{t}+\int_{0}^{1} \mathcal{E}_{t}^{i} B_{t}^{i} d i=\frac{1}{\mathcal{E}_{t+1}^{i}} B_{t+1}^{(i, H)}+\int_{0}^{1} \mathcal{E}_{t+1}^{(i, l)} B_{t+1}^{(i, l)} d l=$ 0 . Using this condition with (9), the equilibrium present discounted nominal value of future aggregate nominal financial wealth is equal to the current level of domestic nominal stock-prices:

$$
E_{t}\left\{F_{t, t+1} \frac{\Omega_{t+1}}{P_{t}}\right\}=\int_{0}^{1} Q_{t}(k) d k=Q_{t},
$$

where we used the intertemporal condition (5). ${ }^{9}$

In equilibrium, real domestic output must be equal to the sum of real labour income and real dividends, implying

$$
D_{t}=\frac{P_{H, t}}{P_{t}} Y_{t}-(1-\vartheta) \frac{W_{t}}{P_{t}} N_{t} .
$$

Letting $\Pi_{t}$ denote the domestic gross inflation rate, the demand side of the domestic economy, characterized by the following Euler equations:

$$
\left(\Sigma_{t}-1\right) C_{t}=\xi Q_{t}+(1-\xi) E_{t}\left\{F_{t, t+1} \Pi_{t+1} \Sigma_{t+1} C_{t+1}\right\},
$$

and

$$
Q_{t}=E_{t}\left\{F_{t, t+1} \Pi_{t+1}\left[Q_{t+1}+D_{t+1}\right]\right\} .
$$

Log-linearizing the demand side of the model gives

$$
\begin{aligned}
y_{t}= & \frac{1}{1+\Psi} E_{t} y_{t+1}+\frac{\Lambda \Psi}{1+\Psi} q_{t}-\frac{\Lambda}{1+\Psi}\left(r_{t}-E_{t} \pi_{t+1}-\rho\right) \\
& -\frac{\alpha \vartheta}{1+\Psi} E_{t} \tilde{s}_{t+1}+\alpha \vartheta \tilde{s}_{t}-\frac{1}{1+\Psi} E_{t}\left(g_{t+1}+y_{t+1}^{*}\right)+\left(g_{t}+y_{t}^{*}\right) \\
& +\left(1-\rho_{\nu}\right)\left(1+\Psi_{\nu}\right) \nu_{t} \\
q_{t}= & \tilde{\beta} E_{t} q_{t+1}+(1-\tilde{\beta}) E_{t} d_{t+1}-\left(r_{t}-E_{t} \pi_{t+1}-\rho\right) \\
d_{t}= & \frac{Y}{D}\left(p_{H, t}-p_{t}+y_{t}\right)-\frac{W N}{P D}\left(n_{t}+w_{t}-p_{t}\right)
\end{aligned}
$$

where $\varphi \equiv \frac{N}{1-N}$ is the inverse of the steady state Frisch elasticity of labor supply, $\Psi \equiv \xi \frac{1-\beta(1-\xi)}{1-\xi} \frac{\Omega}{C}, \rho \equiv-\log \beta, \Psi_{\nu} \equiv \Psi \frac{\beta(1-\xi) \rho_{\nu}}{(1+\Psi)\left(1-\beta(1-\xi) \rho_{\nu}\right)}, \tilde{\beta} \equiv \frac{\beta}{1+\Psi}$, and $\Lambda \equiv(1-\alpha)$.

\footnotetext{
${ }^{9}$ The domestic country is a small country of measure zero, so the bilateral exchange rates in the rest of the world necessarily sum up to one.
} 


\subsection{The Canonical Representation}

The derivation for the supply side of the model is standard and sketched in the appendix. As usual, the reduced form of the model is given in percentage deviations from its steady state:

$$
\begin{aligned}
\tilde{y}_{t}= & \frac{1}{1+\Psi} E_{t} \tilde{y}_{t+1}+\frac{\Lambda \Psi}{1+\Psi} \tilde{q}_{t}-\frac{\Lambda}{1+\Psi}\left(r_{t}-E_{t} \pi_{H, t+1}-r r_{t}^{n}\right) \\
& +\frac{\alpha \Lambda}{1+\Psi} E_{t}\left(\Delta \tilde{s}_{t+1}\right)-\frac{\alpha \vartheta}{1+\Psi} E_{t} \tilde{s}_{t+1}+\alpha \vartheta \tilde{s}_{t} \\
\tilde{q}_{t}= & \tilde{\beta} E_{t} \tilde{q}_{t+1}+(1-\tilde{\beta}) E_{t}\left[\frac{\mu^{p}}{\mu^{p}+\alpha_{y}} \tilde{y}_{t+1}-\frac{1-\alpha_{y}}{\mu^{p}+\alpha_{y}} \tilde{\omega}_{t+1}-\alpha \frac{1+\mu^{p}}{\mu^{p}+\alpha_{y}} \tilde{s}_{t+1}\right] \\
& -\left(r_{t}-E_{t} \pi_{H, t+1}-r r_{t}^{n}\right)+\alpha E_{t} \Delta \tilde{s}_{t+1}+\eta_{t} \\
\pi_{H, t}^{p}= & \phi_{p}\left(\theta_{p} \tilde{\beta} E_{t} \pi_{H, t+1}^{p}+\tau_{p} \pi_{H, t-1}^{p}\right)+\kappa_{p} \tilde{y}_{t}+\lambda_{p} \tilde{\omega}_{t}+\alpha \lambda_{p} \tilde{s}_{t}+u_{t}^{p} \\
\pi_{t}^{w}= & \phi_{w}\left(\theta_{w} \tilde{\beta} E_{t} \pi_{t+1}^{w}+\tau_{w} \pi_{t-1}^{w}\right)+\kappa_{w} \tilde{y}_{t}-\lambda_{w} \tilde{w}_{t}-\frac{\alpha \sigma \vartheta}{\Lambda} \lambda_{w} \tilde{s}_{t}+u_{t}^{w} \\
\tilde{\omega}_{t}= & \tilde{\omega}_{t-1}+\pi_{t}^{w}-\pi_{H, t}^{p}-\alpha \Delta \tilde{s}_{t}+\frac{\alpha_{y}}{1-\alpha_{y}} \Delta y_{t}^{n}-\frac{1}{1-\alpha_{y}} \Delta a_{t} \\
\tilde{s}_{t}= & \sigma_{\alpha} \tilde{y}_{t}
\end{aligned}
$$

where $\tilde{q}_{t} \equiv q_{t}-q_{t}^{n}, \tilde{y}_{t} \equiv y_{t}-y_{t}^{n}, \tilde{s}_{t} \equiv s_{t}-s_{t}^{n}, \tilde{\omega}_{t} \equiv \omega_{t}-\omega_{t}^{n}, \omega_{t} \equiv w_{t}-p_{t}$, and natural variables are given by

$$
\begin{aligned}
y_{t}^{n}= & \alpha \Gamma y_{t}^{*}-\alpha(\Lambda-\vartheta) \Gamma s_{t}^{n}+\Gamma g_{t}+\frac{1+\varphi}{\left(1-\alpha_{y}\right)} \Gamma a_{t}, \\
s_{t}^{n}= & \sigma_{\alpha}\left[y_{t}^{n}-y_{t}^{*}-g_{t}\right], \\
\omega_{t}^{n}= & \log \left(1-\alpha_{y}\right)-\frac{\alpha_{y}}{1-\alpha_{y}} y_{t}^{n}+\frac{1}{1-\alpha_{y}} a_{t}-\alpha s_{t}^{n}, \\
r r_{t}^{n}= & \rho+\Lambda^{-1} E_{t} y_{t+1}^{n}-\frac{1+\psi}{\Lambda} y_{t}^{n}+\Psi q_{t}^{n}+\alpha E_{t}\left(\Delta s_{t+1}^{n}\right)-\frac{\alpha \vartheta}{\Lambda} E_{t} s_{t+1}^{n} \\
& +(1+\Psi)\left(1+\Psi_{\nu}\right)\left(1-\rho_{\nu}\right) \nu_{t} \\
& +\frac{(1+\Psi) \alpha \vartheta}{\Lambda} s_{t}^{n}-\Lambda^{-1} E_{t}\left(g_{t+1}+\alpha y_{t+1}^{*}\right)+\frac{1+\Psi}{\Lambda}\left(g_{t}+\alpha y_{t}^{*}\right) \\
q_{t}^{n}= & \rho+\tilde{\beta} E_{t} q_{t+1}^{n}-r r_{t}^{n}+(1-\tilde{\beta})\left(y_{t+1}^{n}-\alpha s_{t+1}^{n}\right)+\alpha E_{t} \Delta s_{t+1}^{n},
\end{aligned}
$$

and parameters are given by

$$
\begin{aligned}
\lambda_{p} & \equiv \frac{\left(1-\tau_{p}\right)\left(1-\theta_{p}\right)\left(1-\tilde{\beta} \theta_{p}\right)\left(1-\alpha_{y}\right) \mu^{p}}{\mu_{p}+\alpha_{y}} \phi_{p}, \phi_{p} \equiv\left(\theta_{p}+\tau_{p}\left[1-\theta_{p}(1-\tilde{\beta})\right]\right)^{-1} \\
\lambda_{w} & \equiv \frac{\left(1-\tau_{w}\right)\left(1-\theta_{w}\right)\left(1-\tilde{\beta} \theta_{w}\right) \mu^{w}}{\mu^{w}+\varphi\left(1+\mu^{w}\right)} \phi_{w}, \phi_{w} \equiv\left(\theta_{w}+\tau_{w}\left[1-\theta_{w}(1-\tilde{\beta})\right]\right)^{-1} \\
\kappa_{p} & \equiv \frac{\alpha_{y}}{1-\alpha_{y}} \lambda_{p}, \kappa_{w} \equiv\left[\frac{\left(1-\alpha_{y}\right)+\Lambda \varphi}{\left(1-\alpha_{y}\right) \Lambda}\right] \lambda_{w}
\end{aligned}
$$


The shock term $\eta_{t}$ follows the work of Castelnuovo and Nisticó (2010) and accounts for all non-fundamental and time-varying deviations of stock prices from their natural level, which sources lie beyond the scope of our modelling framework here (e.g. variations in the equity premium or other financial shocks).

The model is closed by a Taylor type interest rate rule including a lagged interest rate term and the stock price gap:

$$
r_{t}=\rho+\left(1-\phi_{r}\right)\left(\phi_{p} \pi_{H, t}^{p}+\phi_{y} \tilde{y}_{t}+\phi_{q} \tilde{q}_{t}\right)+\phi_{r} r_{t-1}+u_{t}^{r},
$$

where $u_{t}^{r}$ is a monetary policy shock. We include $\tilde{q}_{t}$ to allow a positive reaction on stock price misalignments.

The exogenous driving forces of the model are

$$
\begin{aligned}
a_{t} & =\rho_{a} a_{t-1}+\varepsilon_{t}^{a}, \\
g_{t} & =\rho_{g} g_{t-1}+\varepsilon_{t}^{g}, \\
\nu_{t} & =\rho_{\nu} \nu_{t-1}+\varepsilon_{t}^{\nu}, \\
y_{t}^{*} & =\rho_{y} y_{t-1}^{*}+\varepsilon_{t}^{y^{*}} \\
u_{t}^{r} & =\rho_{r} u_{t-1}^{r}+\varepsilon_{t}^{r} \\
u_{t}^{p} & =\rho_{p} u_{t-1}^{p}+\varepsilon_{t}^{p}-\chi_{p} \varepsilon_{t-1}^{p} \\
u_{t}^{w} & =\rho_{p} u_{t-1}^{w}+\varepsilon_{t}^{w}-\chi_{w} \varepsilon_{t-1}^{w} \\
\eta_{t} & =\rho_{\eta} \eta_{t-1}+\varepsilon_{t}^{\eta},
\end{aligned}
$$

where all $\varepsilon^{i} \mathbf{S}$ are normally distributed with constant mean and variance $\sigma_{i}^{2}$. The specifications for markup shocks follow the philosophy of Smets and Wouters (2007), who argue that ARMA $(1,1)$ processes are useful to capture the high frequency fluctuations in wage and price mark-ups.

The reduced-form of the DSGE model is founded on structural parameters that describe the optimal behaviour of firms and households. These parameters can be considered independent of the policy regime, and thereby not subject to the Lucas critique. The following section provides the results from a Bayesian estimation procedure and illustrates the properties and policy implications of the estimated model.

\section{Estimation and Model Fit}

For the estimation procedure we use the latest version of DYNARE, a MATLAB pre-processor, which has become the standard for Bayesian estimation of DSGE models over the last years (http://www. dynare.org/). The posterior distributions of the structural parameters are estimated conditional on prior information on the types, the means, and the standard deviations of all distributions, using Maximum Likelihood methods. For this purpose, we apply the Metropolis 
Hastings Markov-Chain Monte Carlo algorithm with four chains à 300,000 draws (neglecting the first 12,000). The scale used for the jumping distribution is set to a value consistent with an acceptance rate in the neighbourhood of $25 \%$ to ensure that we identify also the tails of the distributions correctly. ${ }^{10}$

Calibration and data For some of the structural parameters of the model our dataset can be quite uninformative. This is especially true for parameters, which determine equilibrium outcomes. Therefore we fix some of the parameters before estimation. The discount factor is set to 0.99 , resulting in an annual equilibrium steady state interest rate of roughly 4 percent. The steady-state consumption share is needed to pin down $\frac{\Omega}{C}$ and set to $55 \%$ of total output which is line with the observed consumption share over the sample period. We also fix the international substitution elasticities $\zeta$ and $\varpi$ to 1 . Finally, the mark-ups of prices over marginal costs and wages over the marginal rate of substitution are both set to standard values of 20 percent. ${ }^{11}$

We employ quarterly data for eight macroeconomic variables for the sample period 1971Q1 - 2013Q1: Real output per capita, producer price inflation, nominal wage inflation, stock prices, the nominal interest rate, productivity, foreign demand, and government spending. Note that the start and end-points of the sample are not only driven by data availability at the time of writing the paper, but also to take into account the fact that South Africa moved to a flexible exchange rate regime since 1970 . Barring the data on producer prices, stock price, nominal interest rate, which are obtained from the International Financial Statistics database of the International Monetary Fund, rest of the series are obtained from the South African Reserve Bank database. Real output per capita is measured by 'real gross domestic product' divided by 'population'. Concerning prices and wages we use 'producer or wholesale prices' and 'nominal wage'. Both quarterly inflation rates are derived by dividing the annual percentage change in prices by four: $\left(\frac{P_{t}-P_{t-4}}{P_{t-4}}\right) / 4$. For productivity we use 'manufacturing labour productivity', and 'final consumption expenditure by general government to GDP' is used for government expenditures. Stock prices are measured by the 'all share price index', and finally, we use the '3-month money market rate' as interest rate. Since the latter series is given in percent per annum we transform the series in percent per quarter. All series have been seasonally adjusted before any transformation, detrended using an HP-Filter with smoothing parameter 1600.

\footnotetext{
${ }^{10}$ See An and Schorfheide (2007) for details on the Bayesian estimation procedure.

${ }^{11}$ The average annual interest rate in South Africa over the sample is about 10 percent, implying a discount factor of 0.975 . Since we believe this rate not to be the steady state, we used the standard value of 0.99 . Estimations with $\beta=0.975$ did not change the results notably and are available on request. We also estimated the model with mark-ups of 10 percent without a considerable effect on the estimations.
} 
Prior and Posterior Distributions and Properties of the Estimated Model The choice of a prior distribution can be crucial for the estimation procedure. We rely on estimations of DSGE models for South Africa of Steinbach et al. (2009), Alpanda et al. (2010a,b, 2011), and Gupta and Steinbach (2013). The prior distributions for the Calvo lottery and for the persistence parameters, for example, are also used in Alpanda et al. (2011). The priors for the Taylor rule are standard and used in Steinbach et al. (2009) and Alpanda et al. (2010b). Contrary to these papers, we include an interest rate smoothing parameter and choose a $\beta(0.5,0.2)$ distribution. Since none of the cited studies has an equivalent to the degree of openness, we decided to use a value of 50 percent as prior mean.

The focus of our estimation lies on the parameters $\zeta$ and $\phi_{q}$. For the prior mean of the probability of dying we choose a value of one third, implying a decision horizon of 3 quarters. We believe this to be realistic for a decision on the portfolio of stock traders. Since we are neither sure about the sign nor the size of a possible reaction of the interest rate with respect to the stock price gap, we choose a standard normal distribution for $\phi_{q}$. All prior distributions and estimation results are summarized in Table 1 (a graphical representation can be found in appendix A.2).

The table provides the results on the estimation of the model including wealth effects as well as those for a standard New Keynesian model with $\zeta=0$ and $\phi_{q}=0$. Comparing our results with those in the literature, we find that all standard parameter estimations are in a plausible range. The results on the wealth effects suggest a decision horizon of one and a half year, which is longer than expected, but not extraordinary high. In contrast to the estimations of VAR- and VEC-models mentioned above, our results do not indicate a positive reaction of the interest rate on stock price misalignments.

To illustrate the properties of the model and to show that our estimated shock processes match the data, Figure 5 shows the original data series and those generated from our estimated shock processes. These graphs suggest that our model performs very well in replicating the data. In addition, Table 2 compares the moments of the data and the estimated model for the most important variables. The last column 'NKM' refers to the standard New Keynesian model without wealth effects. These numbers show that both model variants match the standard deviations quite well, but our variant is also able to capture the correlation between stock prices and output. 
Table 1: Bayesian Estimation Results

\begin{tabular}{|c|c|c|c|c|c|c|}
\hline DESCRIPTION & & PRIOR & \multicolumn{2}{|c|}{$\begin{array}{c}\text { WEALTH EFFECTS } \\
\text { POSTERIOR }\end{array}$} & \multicolumn{2}{|c|}{$\begin{array}{l}\text { STANDARD NKM } \\
\text { POSTERIOR }\end{array}$} \\
\hline \multicolumn{7}{|c|}{ STRUCTURAL PARAMETERS } \\
\hline Probability of Dying & $\zeta$ & $\beta(0.33,0.05)$ & 0.16 & $(0.13,0.18)$ & - & - \\
\hline Calvo Price Stickiness & $\theta_{p}$ & $\beta(0.5,0.2)$ & 0.81 & $(0.72,0.90)$ & 0.79 & $(0.69,0.89)$ \\
\hline Calvo Wage Stickiness & $\theta_{w}$ & $\beta(0.5,0.2)$ & 0.64 & $(0.52,0.77)$ & 0.65 & $(0.52,0.77)$ \\
\hline BW-Looking Price-Setters & $\tau_{p}$ & $\beta(0.5,0.2)$ & 0.43 & $(0.34,0.52)$ & 0.45 & $(0.35,0.55)$ \\
\hline BW-Looking Wage-Setters & $\tau_{w}$ & $\beta(0.5,0.2)$ & 0.39 & $(0.26,0.53)$ & 0.46 & $(0.31,0.60)$ \\
\hline Inverse Frisch Elasticity & $\varphi$ & $\Gamma(1,0.5)$ & 1.90 & $(0.66,3.05)$ & 1.49 & $(0.42,2.51)$ \\
\hline e of Openness & $\alpha$ & $\beta(0.5,0.2)$ & 0.44 & $(0.40,0.48)$ & 0.45 & $(0.41,0.49)$ \\
\hline \multicolumn{7}{|c|}{ TAYLOR RULE PARAMETERS } \\
\hline Interest rate smoothing & $\phi_{r}$ & $\beta(0.5,0.2)$ & 0.85 & $(0.81,0.90)$ & 0.87 & $(0.83,0.92)$ \\
\hline Inflation & $\phi_{p}$ & $\Gamma(1.5,0.2)$ & 1.24 & $(0.97,1.52)$ & 1.19 & $(0.93,1.45)$ \\
\hline Output Gap & $\phi_{y}$ & $\Gamma(0.5,0.2)$ & 1.43 & $(1.03,1.83)$ & 1.43 & $(1.03,1.84)$ \\
\hline Stock Price Gap & $\phi_{q}$ & $\mathcal{N}(0,1)$ & -0.04 & $(-0.07,-0.02)$ & - & - \\
\hline \multicolumn{7}{|c|}{ STANDARD DEVIATION OF SHOCKS } \\
\hline Productivity & $\sigma_{a}$ & $\Gamma^{-1}(0.001,2)$ & 2.50 & $(1.58,1.88)$ & 1.73 & $(1.57,1.88)$ \\
\hline Price Mark-Up & $\sigma_{p}$ & $\Gamma^{-1}(0.001,2)$ & 0.13 & $(0.12,0.18)$ & 0.15 & $(0.12,0.18)$ \\
\hline Wage Mark-Up & $\sigma_{w}$ & $\Gamma^{-1}(0.001,2)$ & 1.15 & $(0.18,0.27)$ & 0.23 & $(0.19,0.28)$ \\
\hline Preference & $\sigma_{\nu}$ & $\Gamma^{-1}(0.001,2)$ & 5.60 & $(4.06,6.74)$ & 4.48 & $(3.44,5.48)$ \\
\hline Foreign Demand & $\sigma_{y^{*}}$ & $\Gamma^{-1}(0.001,2)$ & 0.53 & $(0.48,0.57)$ & 0.54 & $(0.49,0.59)$ \\
\hline Monetary Policy & $\sigma_{r}$ & $\Gamma^{-1}(0.001,2)$ & 0.30 & $(0.25,0.34)$ & 0.30 & $(0.26,0.34)$ \\
\hline Stock Market & $\sigma_{\eta}$ & $\Gamma^{-1}(0.001,2)$ & 2.32 & $(1.70,3.06)$ & 1.30 & $(0.68,1.87)$ \\
\hline Government Expenditures & $\sigma_{g}$ & $\Gamma^{-1}(0.001,2)$ & 0.54 & $(0.49,0.59)$ & 0.54 & $(0.49,0.59)$ \\
\hline \multicolumn{7}{|c|}{ AR \& MA PARAMETERS } \\
\hline Productivity & $\rho_{a}$ & $\beta(0.5,0.2)$ & 0.74 & $(0.66,0.82)$ & 0.75 & $(0.67,0.83)$ \\
\hline Price Mark-Up & $\rho_{p}$ & $\beta(0.5,0.2)$ & 0.53 & $(0.41,0.64)$ & 0.51 & $(0.39,0.63)$ \\
\hline Wage Mark-Up & $\rho_{w}$ & $\beta(0.5,0.2)$ & 0.43 & $(0.18,0.67)$ & 0.41 & $(0.15,0.66)$ \\
\hline Price Mark-Up & $\chi_{p}$ & $\beta(0.3,0.15)$ & 0.07 & $(0.00,0.15)$ & 0.07 & $(0.00,0.16)$ \\
\hline Wage Mark-Up & $\chi_{w}$ & $\beta(0.3,0.15)$ & 0.28 & $(0.02,0.51)$ & 0.31 & $(0.02,0.55)$ \\
\hline Foreign Demand & $\rho_{y^{*}}$ & $\beta(0.5,0.2)$ & 0.84 & $(0.77,0.91)$ & 0.78 & $(0.73,0.83)$ \\
\hline Monetary Policy & $\rho_{r}$ & $\beta(0.5,0.2)$ & 0.41 & $(0.24,0.59)$ & 0.39 & $(0.21,0.57)$ \\
\hline Preference & $\rho_{\nu}$ & $\beta(0.5,0.2)$ & 0.83 & $(0.77,0.88)$ & 0.83 & $(0.78,0.89)$ \\
\hline Stock Market & $\rho_{\eta}$ & $\beta(0.5,0.2)$ & 0.78 & $(0.72,0.85)$ & 0.86 & $(0.80,0.93)$ \\
\hline Government Expenditures & $\rho_{g}$ & $\beta(0.5,0.2)$ & 0.65 & $(0.56,0.75)$ & 0.67 & $(0.57,0.76)$ \\
\hline
\end{tabular}

Notes: Prior distributions (mean and variance in brackets), and means of the posterior distributions derived from the draws of the Metropolis-Hastings algorithm (95 percent intervals in brackets). 
Figure 1: Estimated Dynamics and Original Data Series

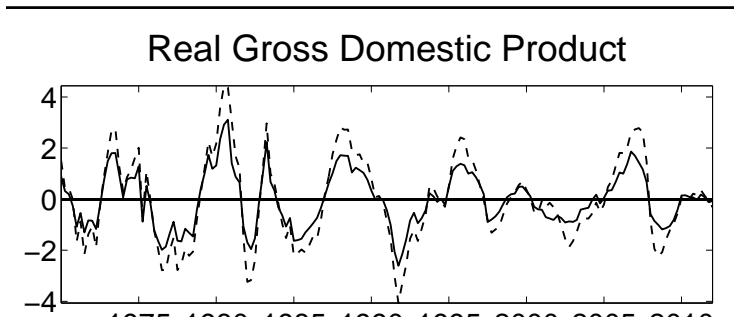

19751980198519901995200020052010

Producer Price Inflation

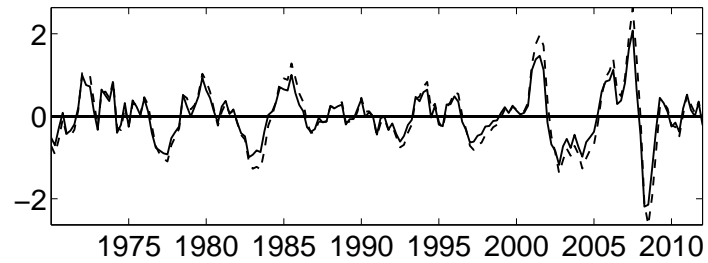

3-Month Nominal Interest Rate

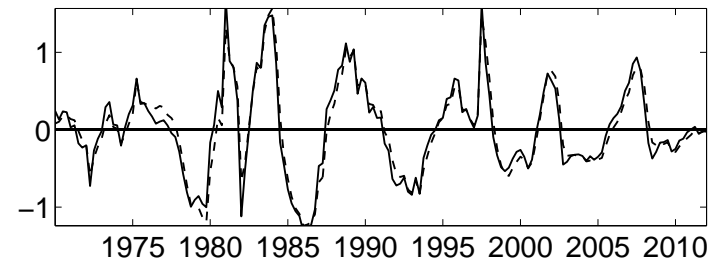

Productivity

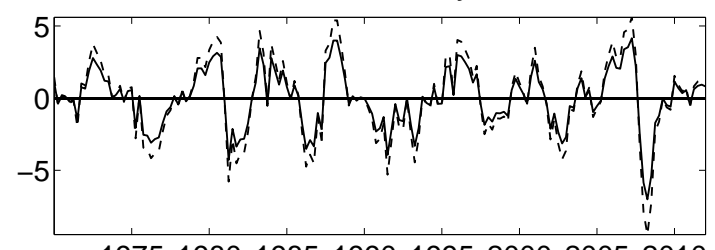

19751980198519901995200020052010
Stock Price Index

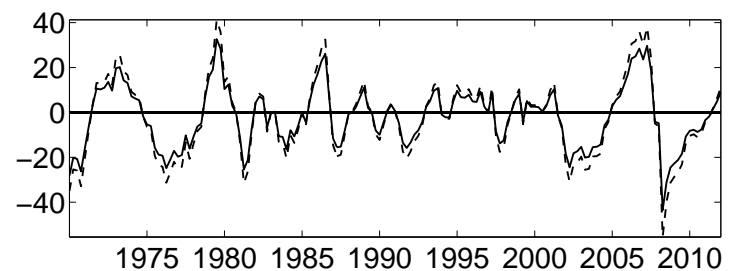

Nominal Wage Inflation

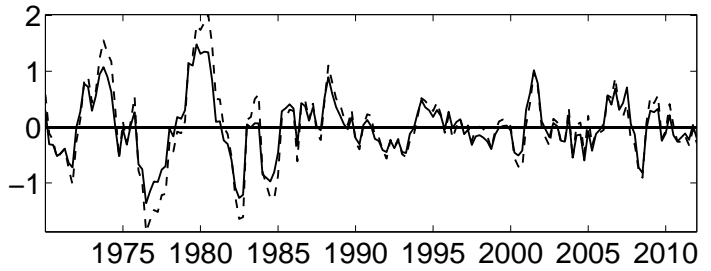

Government Expenditures

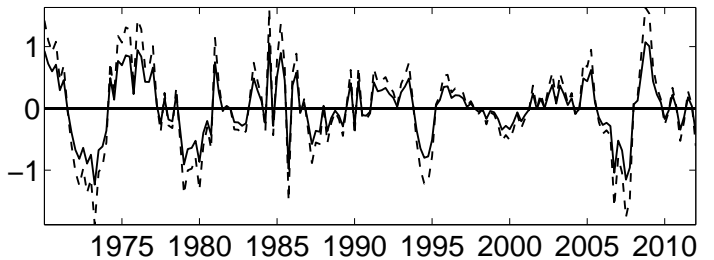

Foreign Demand

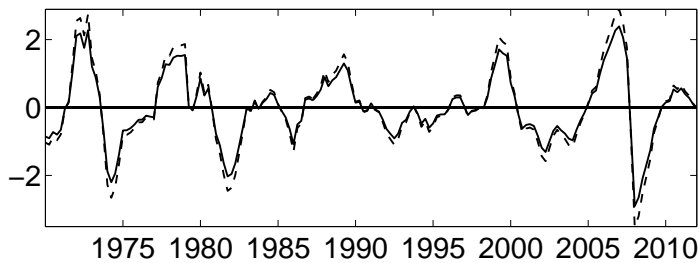

Dashed Line: Orignal Data, Solid Line: Model Generated Series.

Table 2: Theoretical and Empirical Moments

\begin{tabular}{|c|c|c|c|c|c|c|c|}
\hline \multicolumn{4}{|c|}{ STANDARD DEVIATIONS } & \multicolumn{4}{|c|}{ CORRELATIONS } \\
\hline & DATA & MODEL & NKM & & DATA & MODEL & NKM \\
\hline OUTPUT GAP $(Y)$ & 1.66 & 1.97 & 1.86 & $Q, Y$ & 0.42 & 0.39 & 0.08 \\
\hline STOCK PRICE GAP $(Q)$ & 17.02 & 14.77 & 17.42 & $Q, \Pi_{h}$ & 0.57 & 0.06 & 0.01 \\
\hline PRICE INFLATION $\left(\Pi_{h}\right)$ & 0.75 & 0.66 & 0.67 & $Q, \Pi_{w}$ & 0.52 & 0.06 & 0.00 \\
\hline WAGE INFLATION $\left(\Pi_{w}\right)$ & 0.68 & 0.63 & 0.65 & $Q, R$ & -0.26 & 0.12 & 0.02 \\
\hline INTEREST RATE $(R)$ & 0.51 & 1.17 & 1.04 & $Q, A$ & 0.48 & 0.00 & 0.00 \\
\hline PRODUCTIVITY $(A)$ & 2.66 & 2.56 & 2.60 & $Q, G$ & -0.33 & 0.01 & 0.01 \\
\hline GOVERNMENT EXP. $(G)$ & 0.70 & 0.73 & 0.73 & $Q, Y^{*}$ & 0.48 & 0.04 & 0.03 \\
\hline FOREIGN DEMAND $\left(Y^{*}\right)$ & 1.18 & 0.96 & 0.86 & & & & \\
\hline
\end{tabular}


Impulse Responses and Variance Decompostion In the following we study the dynamics of the estimated model. Bayesian Impulse Response Functions may help illustrating the consequences of specific shocks. The Figures 2 and 3 provide the impulse responses and the 95 percent interval derived from the posterior distributions of our Metropolis-Hastings iterations. Positive stock market, preference and foreign demand shocks represent an increase in demand and imply an increase in production, prices, wages, and the stock price gap. ${ }^{12}$ Consequently, the central bank increases the interest rate to calm down the economy. A positive monetary policy shock implies the opposite: As the increase in the real interest rate dampens demand, output and inflation rates significantly fall, and so does the stock price gap. Note, that the reaction of the stock price gap on a financial shock is more than 10 times higher than for any other shock.

Figure 2: Bayesian Impulse Response Functions

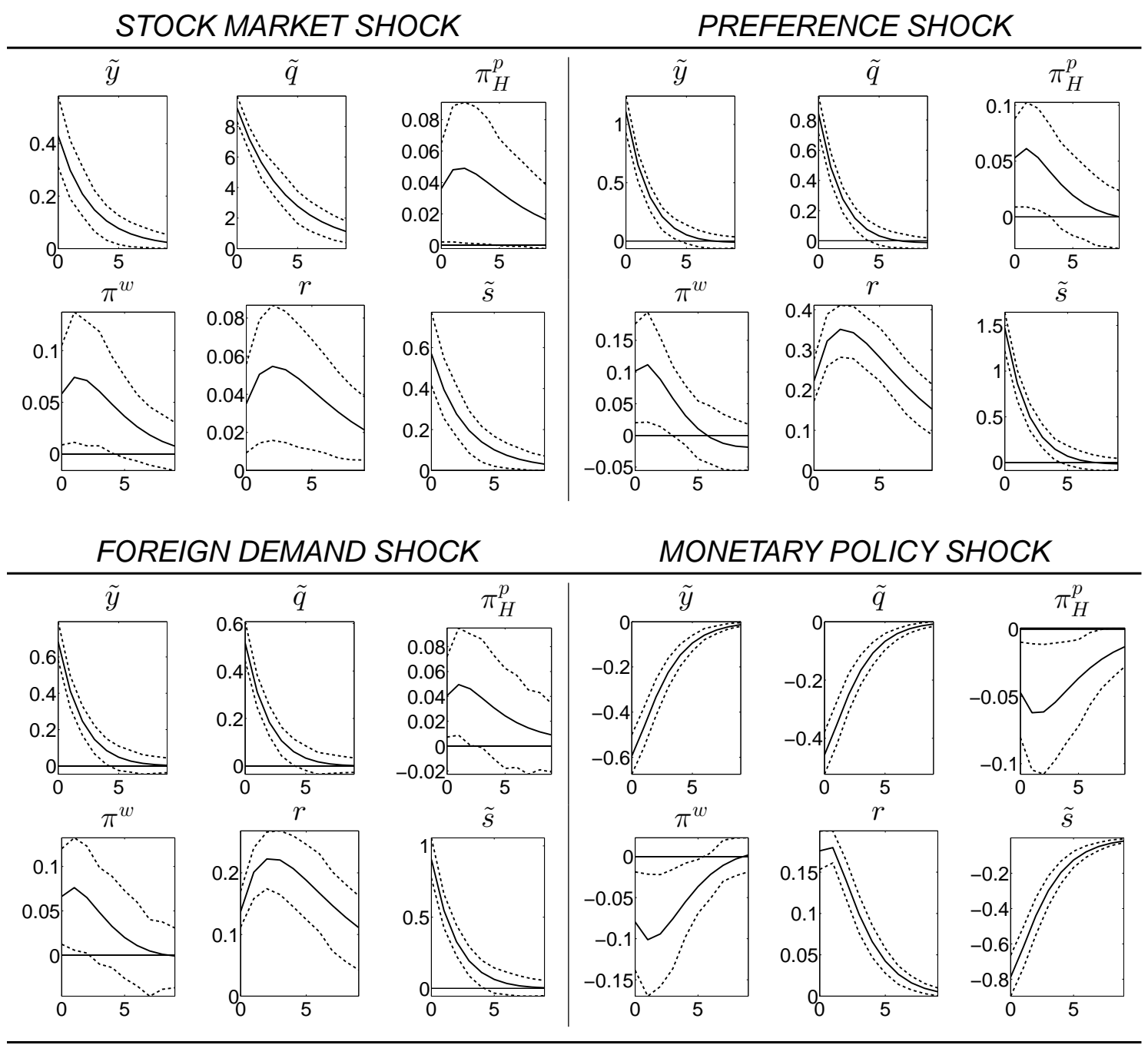

Solid Line: Posterior mean, Dashed Line: 95 percent interval.

${ }^{12}$ Since real wages increase too slow, the real wage gap turns negative 
Figure 3: Bayesian Impulse Response Functions II

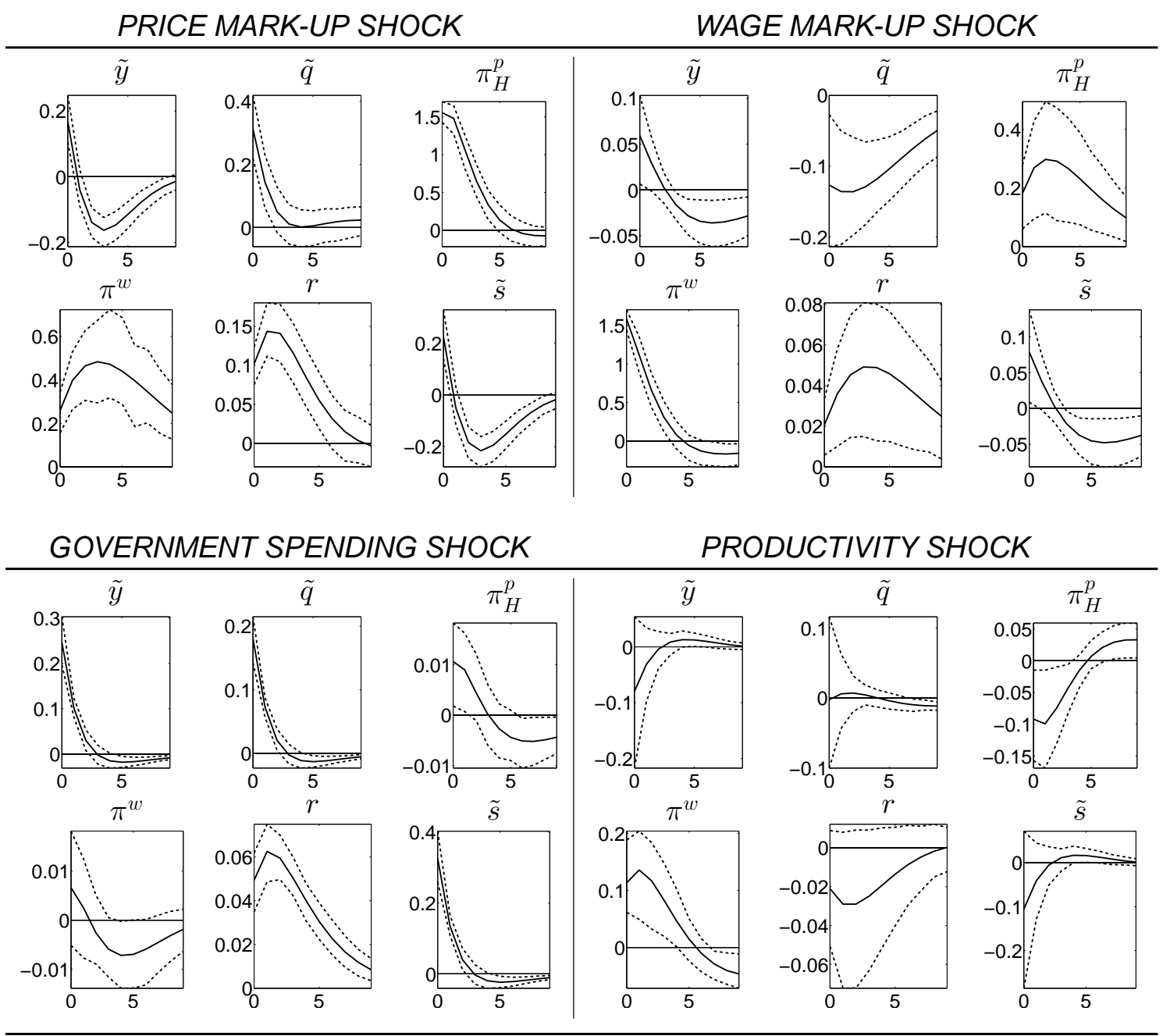

Solid Line: Posterior mean, Dashed Line: 95 percent interval.

The output reactions after price and wage mark-up shocks are positive for one quarter due to the high persistence of the interest rate, which implies a negative real rate, thereby encouraging consumption. However, as the interest rate increases further, the output gap turns negative. Concerning the stock price dynamics, the reactions after both mark-up shocks differ substantially: While an increase in prices has a positive effect on stock prices (due to a falling real interest rate), increasing wages lead to falling dividends and have a negative impact on the stock price gap. Government spending shocks increase demand and show a similar pattern as the shocks above. For an increase in productivity, the flexible price level of output increases stronger than actual output and implies a negative output gap and falling inflation.

To identify the sources of of the South African business cycle, Table 3 provides a variance decomposition at different time horizons. The table illustrates that production at business cycle frequencies is primarily driven by demand, as 65 75 percent of output fluctuations are driven by preferences and foreign demand 
Table 3: Conditional Variance Decomposition at Different Horizons

\begin{tabular}{|c|c|c|c|c|c|c|c|c|c|}
\hline VARIABLE AND HORIZON & & $a$ & $g$ & $\nu$ & $y^{*}$ & $r$ & $p$ & $w$ & $\eta$ \\
\hline \multirow[t]{5}{*}{ OUTPUT } & 1 & 0.40 & 2.53 & 53.98 & 19.47 & 14.58 & 1.11 & 0.16 & 7.77 \\
\hline & 2 & 0.34 & 2.15 & 52.15 & 19.10 & 16.93 & 0.87 & 0.14 & 8.31 \\
\hline & 4 & 0.29 & 1.88 & 49.75 & 18.52 & 18.49 & 2.04 & 0.13 & 8.89 \\
\hline & 8 & 0.30 & 1.85 & 48.56 & 18.18 & 18.65 & 3.07 & 0.25 & 9.16 \\
\hline & $\infty$ & 0.30 & 1.85 & 48.47 & 18.14 & 18.62 & 3.09 & 0.34 & 9.20 \\
\hline \multirow[t]{5}{*}{ STOCK PRICES } & 1 & 0.00 & 0.04 & 0.83 & 0.30 & 0.23 & 0.11 & 0.02 & 98.47 \\
\hline & 2 & 0.00 & 0.03 & 0.69 & 0.25 & 0.23 & 0.09 & 0.02 & 98.68 \\
\hline & 4 & 0.00 & 0.02 & 0.56 & 0.21 & 0.21 & 0.06 & 0.03 & 98.90 \\
\hline & 8 & 0.00 & 0.02 & 0.50 & 0.19 & 0.19 & 0.06 & 0.05 & 99.00 \\
\hline & $\infty$ & 0.00 & 0.02 & 0.49 & 0.18 & 0.19 & 0.06 & 0.05 & 99.01 \\
\hline \multirow[t]{5}{*}{ PRODUCER PRICE INFLATION } & 1 & 0.33 & 0.00 & 0.12 & 0.06 & 0.08 & 97.84 & 1.51 & 0.05 \\
\hline & 2 & 0.37 & 0.00 & 0.14 & 0.08 & 0.12 & 96.73 & 2.49 & 0.07 \\
\hline & 4 & 0.39 & 0.00 & 0.18 & 0.10 & 0.18 & 94.22 & 4.81 & 0.12 \\
\hline & 8 & 0.39 & 0.00 & 0.20 & 0.12 & 0.23 & 91.26 & 7.63 & 0.17 \\
\hline & $\infty$ & 0.47 & 0.00 & 0.20 & 0.12 & 0.23 & 90.59 & 8.20 & 0.19 \\
\hline \multirow[t]{5}{*}{ WAGE INFLATION } & 1 & 0.38 & 0.00 & 0.40 & 0.16 & 0.22 & 2.35 & 96.35 & 0.13 \\
\hline & 2 & 0.59 & 0.00 & 0.57 & 0.23 & 0.37 & 5.05 & 92.97 & 0.21 \\
\hline & 4 & 0.76 & 0.00 & 0.68 & 0.30 & 0.55 & 12.01 & 85.36 & 0.34 \\
\hline & 8 & 0.71 & 0.00 & 0.62 & 0.28 & 0.55 & 21.06 & 76.40 & 0.37 \\
\hline & $\infty$ & 0.86 & 0.00 & 0.61 & 0.27 & 0.52 & 23.59 & 73.79 & 0.35 \\
\hline \multirow[t]{5}{*}{ INTEREST RATE } & 1 & 0.50 & 2.11 & 45.11 & 16.33 & 25.66 & 8.97 & 0.43 & 0.89 \\
\hline & 2 & 0.51 & 1.98 & 49.31 & 18.17 & 18.87 & 9.57 & 0.61 & 0.96 \\
\hline & 4 & 0.48 & 1.70 & 54.53 & 20.73 & 12.02 & 8.55 & 0.95 & 1.04 \\
\hline & 8 & 0.38 & 1.37 & 58.26 & 23.14 & 8.17 & 6.28 & 1.32 & 1.07 \\
\hline & $\infty$ & 0.35 & 1.24 & 58.87 & 24.19 & 7.27 & 5.64 & 1.40 & 1.04 \\
\hline
\end{tabular}

shocks. Nevertheless, financial perturbations explain up to 9.2 percent of the volatility of production. On the other hand, stock prices are almost completely driven by shocks from the financial markets. In a nutshell, these results suggest a one-sided decoupling of financial markets from the real economy: While financial shocks increase the volatility of production (and hence employment), shocks from the rest of the economy seem not to affect the stock price dynamics at all.

A Counterfactual Experiment Our results do not indicate a significant reaction of the central bank on stock price misalignments. In the following, we will investigate, whether a positive reaction of the nominal interest rate would have dampened the business cycle. Therefore we simulate the model using the shocks identified in our estimation under the assumption of $\phi_{q}=0.5$. The results are given in Figure 4 and provide a clear result: A dampening effect of monetary policy on stock price volatility can only be achieved at dramatic costs in terms of higher output volatility. While the standard deviation of the stock price gap decreases from 15.14 to 12.39 , the standard deviation of output more than doubles (from 1.52 to 3.19), and that of the interest rate increases from 0.59 to 0.90 . Given these numbers, the SARB is well advised not to use the interest rate to calm down financial 
Figure 4: A positive interest rate reaction on stock price misalignments $\left(\phi_{q}=0.5\right)$.

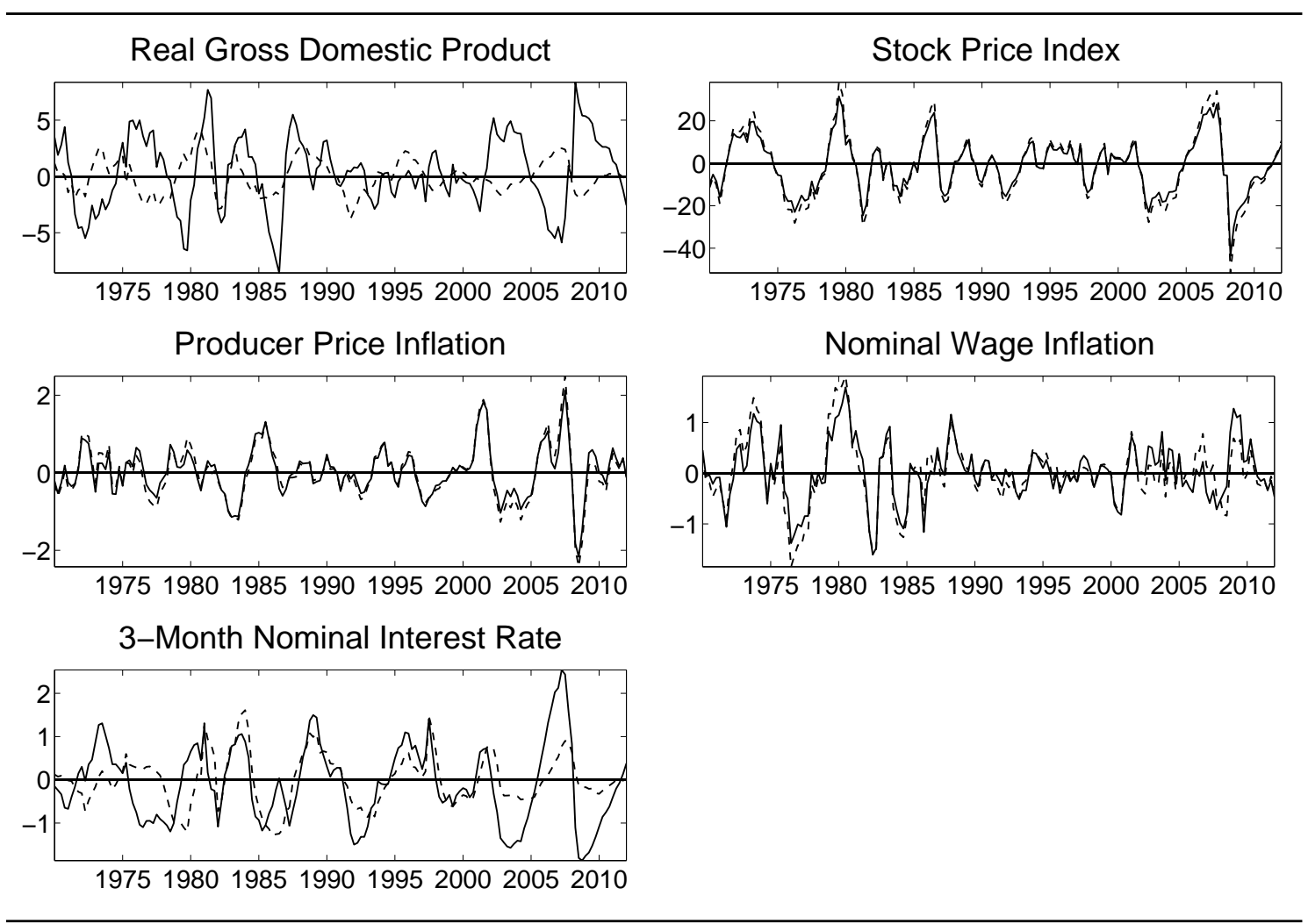

Dashed Line: Orignal Data, Solid Line: $\phi_{q}=0.5$.

markets.

\section{Conclusions}

The aim of this paper was to quantify the effects of stock price wealth on the South African business cycle. The estimation of our perpetual youth SOE-DSGE model suggests a decision horizon of one and a half year and indicates a significant effect of stock price misalignments on output volatility: Up to 9.2 percent of the production variance can be explained by financial perturbations. Concerning the interest rate we did neither find a positive reaction of the SARB on the stock price gap nor a considerable implicit impact of stock prices on the volatility of the interest rate (via the impact on output, for example). Moreover, simulating the estimated model with a modified Taylor rule, which includes a positive reaction of the interest rate on the stock price gap, clearly suggests that a dampening effect on financial markets can only be achieved at dramatically high costs in terms of higher output volatility. Given the difficulty to identify a stock price misalignment, these results suggest that the SARB is well-advised, not to found their interest rate decision on financial market turbulences.

In addition, we found a one-sided decoupling of the stock market from the 
real economy: While financial shocks that lead to ups and downs in stock prices have an impact on real activity, shocks from the real side of the economy have no impact on stock price dynamics at all. In the short-run, stock prices seem to be purely shock driven. Hence, policymakers might be searching for a different instrument to get the consequences of these financial disturbances under control. The question about this instrument will be an important guideline for future research.

\section{A Appendix}

\section{A.1 About the Model}

In what follows we provide a sketch of the optimisation problems faced by domestic firms (A.1.1), the intratemporal allocation of domestic households and the optimal wage setting scheme (A.1.2), the risk sharing of households via the trading of bonds (A.1.3), and the derivation of the New Keynesian price and wage inflation curves (A.1.4).

\section{A.1.1 Firms}

Retailers Retailers produce competitively a final good $Y_{t}$ by means of a CRS production function, using intermediate goods $Y_{t}(k)$ as inputs:

$$
Y_{t}=\left[\int_{0}^{1} Y_{t}(k)^{\frac{1}{1+\mu_{t}^{p}}} d l\right]^{1+\mu_{t}^{p}},
$$

where $\mu_{t}^{p}$ captures the time-varying mark-up of prices over marginal cost in the wholesale sector and is usually referred to as a cost-push shock. ${ }^{13}$

Profit maximization in the retail sector leads to the following demand functions for intermediates:

$$
Y_{t}(k)=\left[\frac{P_{H, t}(k)}{P_{H, t}}\right]^{-\frac{1+\mu_{t}^{p}}{\mu_{t}^{t}}} Y_{t},
$$

where $P_{H, t} \equiv\left[P_{H, t}(k)^{1 / \mu_{t}^{p}} d l\right]^{-\mu_{t}^{p}}$ represents the aggregate domestic producer price index.

The Wholesale Sector Differentiated intermediate goods are produced using Cobb-Douglas production function

$$
Y_{t}(k)=A_{t} N_{t}^{1-\alpha_{Y}}(k),
$$

\footnotetext{
${ }^{13}$ Variations in $\mu_{t}^{p}$ represent time-varying gaps between the natural level of output and the efficient one, which can be due to time-varying market power or fluctuations in labour tax income, for example.
} 
where $A_{t} \equiv \exp \left(a_{t}\right)$ represents labour-augmenting productivity, and $a_{t}$ is an exogenous disturbance, following an AR(1)-process, and

$$
N_{t}(k) \equiv\left[\int_{0}^{1} N_{t}(k, l)^{\frac{1}{1+\mu_{t}^{w}}}\right]^{1+\mu_{t}^{w}},
$$

is a composite index of the different types of labour $l$ employed by a firm $k$ $\left(N_{t}(k, l)\right)$, with $\mu_{t}^{w}$ capturing the time-varying mark-up of real wages over the marginal rate of substitution between consumption and leisure (due to the market power of households/workers).

Consequently, cost minimization implies a demand schedule for each type of labour $l$ for a given nominal wage rate $W_{t}(l)$ :

$$
N_{t}(k, l)=\left[\frac{W_{t}(l)}{W_{t}}\right]^{-\frac{1+\mu_{w}^{w}}{\mu_{t}^{w}}} N_{t}(k),
$$

where $W_{t} \equiv\left[W_{t}(l)^{1 / \mu_{t}^{w}} d l\right]^{-\mu_{t}^{w}}$ represents the aggregate nominal wage index. Hence, the aggregate wage bill can be expressed as $\int_{0}^{1} W_{t}(l) N_{t}(k, l) d l=W_{t} N_{t}(k)$.

Aggregating across domestic brands using the demand functions (36) leads to

$$
Y_{t} \wp_{t}=A_{t} N_{t}
$$

where $\wp_{t} \equiv \int_{0}^{1}\left(\frac{P_{H, t}(k)}{P_{H, t}}\right)^{-\frac{1+\mu_{\psi}^{p}}{\left(1-\alpha_{Y}\right) \mu_{t}^{p}}} d k$ measures the relative price dispersion among domestic firms and $N_{t}=\int_{0}^{1} N_{t}(k) d k$ represents the aggregate per-capita amount of hours worked.

Price Setting Monopolistically competitive firms are assumed to set prices in a Calvo-staggered manner: A randomly selected fraction of firms $\left(1-\theta_{p}\right)$ adjusts prices while the remaining fraction of firms $\theta_{p}$ does not adjust. In addition, a fraction of $\left(1-\tau_{p}\right)$ firms behaves in a forward-looking way and the remaining fraction $\tau_{p}$ uses the recent history of the aggregate price index when they set prices. Thus $\tau_{p}$ is a measure of the degree of backward-looking price-setting.

All forward-looking firms, that reset prices in $t$, choose the same price $P_{H, t}^{f l}$, since they face the same optimization problem,

$$
\max _{\left\{P_{H, t}^{f l}\right\}} E_{t} \sum_{i=0}^{\infty} \theta_{p}^{i} F_{t, t+i} \frac{1}{\mu_{t+i}^{p}} Y_{t+i \mid t}\left[P_{H, t}^{f l}-\left(1+\mu_{t+i}^{p}\right) M C_{t+i \mid t} P_{H, t+i}\right],
$$

where $P_{H, t}^{f l}$ represents optimal price of a forward-looking firm, resetting prices in period $t, F_{t, t+i}$ represents the real discount factor, and $M C_{t+i \mid t}$ and $Y_{t+i \mid t}$ represent real marginal cost and output in $t+i$ of a firm, that reset prices in $t$, respectively. 
Optimisation leads to the following log-linearized price-setting rule:

$$
p_{H, t}^{f l}=\mu_{t}^{p}+\left(1-\tilde{\beta} \theta_{p}\right) \sum_{i=0}^{\infty}\left(\tilde{\beta} \theta_{p}\right)^{i} E_{t}\left(\frac{(1-\alpha) \mu^{p}}{\mu^{p}+\alpha} m c_{t+i \mid t}+p_{t+i}\right) \text {. }
$$

Defining the domestic index for the prices newly set in period $t\left(\bar{P}_{H, t}^{n}\right)$ as a weighted average of the forward- and backward-looking prices, and assuming a rule of thumb for the backward-looking price-setters,

$$
P_{H, t}^{b l}=\bar{P}_{H, t-1}^{n}+\pi_{H, t-1,}^{p}
$$

the following equations can be derived using some straightforward algebra:

$$
\begin{aligned}
& P_{H, t}= {\left[\theta_{p} P_{H, t-1}^{1-\theta_{p}}+\left(1-\theta_{p}\right)\left(\bar{P}_{H, t}^{n}\right)^{1-\theta_{p}}\right]^{\frac{1}{1-\theta_{p}}}, } \\
& \bar{P}_{H, t}^{n}=\left(1-\tau_{p}\right) P_{H, t}^{f l}+\tau_{p} P_{H, t}^{b l},
\end{aligned}
$$

where $\pi_{H, t}^{p}=\ln \left(\frac{P_{H, t}}{P_{H, t-1}}\right)$ represents the domestic producer price inflation.

\section{A.1.2 Households}

Intratemporal Allocation We now proceed to illustrate the intratemporal allocation. The composite consumption index of a domestic cohort $j$ of labour type $l$ is a Dixit-Stiglitz aggregate over differentiated domestic and foreign goods,

$$
C_{t}(j, l) \equiv\left[(1-\alpha)^{\frac{1}{\varpi}} C_{H, t}(j, l)^{\frac{\varpi-1}{\varpi}}+\alpha^{\frac{1}{\varpi}} C_{F, t}(j, l)^{\frac{\omega-1}{\varpi}}\right]^{\frac{\varpi}{\varpi-1}},
$$

where $C_{H, t}(j, l)$ and $C_{F, t}(j, l)$ represent the domestic demand for domestic and foreign final goods, respectively, $\varpi>0$ represents the elasticity of substitution between domestic and foreign goods, and $\alpha$ refers to the share of domestic consumption allocated to imported goods and is thus a natural index of openness. Furthermore, the demand indices are given by the following CES functions:

$$
\begin{aligned}
C_{H, t}(j, l) & \equiv\left[\int_{0}^{1} C_{H, t}(k, j, l)^{\frac{\varepsilon-1}{\varepsilon}} d k\right]^{\frac{\varepsilon}{\varepsilon-1}}, C_{F, t}(j, l) \equiv\left[\int_{0}^{1} C_{i, t}(j, l)^{\frac{\zeta-1}{\zeta}} d i\right]^{\frac{\zeta}{\zeta-1}}, \\
C_{i, t}(j, l) & \equiv\left[\int_{0}^{1} C_{i, t}(k, j, l)^{\frac{\varepsilon-1}{\varepsilon}} d k\right]^{\frac{\varepsilon}{\varepsilon-1}},
\end{aligned}
$$

where $\varepsilon$ denotes the elasticity of substitution between the differentiated goods within one single country and $\zeta$ measures the substitutability between goods produced in different foreign countries. $C_{H, t}(k, j, l)$ and $C_{i, t}(k, j, l)$ represent the domestic demand of cohort $j$ for a specific domestic product or a specific product from country $i$, respectively. $C_{i, t}(j, l)$ is a composite index, summarizing the de- 
mand for products from country $i$, and $C_{F, t}(j, l)$ is a composite index, summarizing the demand for products from all foreign countries.

Similar to the consumption indices, household's minimization of total expenditures yields the following producer price indices (PPIs) for domestic and foreign goods, $P_{H, t}=\left[\int_{0}^{1} P_{H, t}(k)^{1-\varepsilon} d k\right]^{\frac{1}{1-\varepsilon}}, P_{F, t}=\left[\int_{0}^{1} P_{i, t}^{1-\zeta} d i\right]^{\frac{1}{1-\zeta}}, P_{i, t}=\left[\int_{0}^{1} P_{i, t}(k)^{1-\varepsilon} d k\right]^{\frac{1}{1-\varepsilon}}$. Consequently, the domestic CPI is given by:

$$
P_{t} \equiv\left[(1-\alpha) P_{H, t}^{(1-\varpi)}+\alpha P_{F, t}^{(1-\varpi)}\right]^{\frac{1}{1-\varpi}} .
$$

Following the preceding equations, optimal allocation of any given expenditure yields the following demand equations

$$
\begin{aligned}
C_{H, t}(j, l) & =(1-\alpha)\left(\frac{P_{H, t}}{P_{t}}\right)^{-\varpi} C_{t}(j, l), \\
C_{F, t}(j, l) & =\alpha\left(\frac{P_{F, t}}{P_{t}}\right)^{-\varpi} C_{t}(j, l), C_{i, t}(j, l)=\left(\frac{P_{i, t}}{P_{F, t}}\right)^{-\zeta} C_{F, t}(j, l) .
\end{aligned}
$$

Wage Setting Analogously to the price setting procedure of firms, only a randomly a selected fraction of households $\left(1-\theta_{w}\right)$ is able to adjust wages in each period, and only a fraction of $\left(1-\tau_{w}\right)$ does so in a forward-looking manner. All households referring to the latter fraction choose the same optimal wage $W_{t}^{f l}$ following

$$
\max _{\left\{W_{t}^{f l}\right\}} E_{t} \sum_{i=0}^{\infty} \theta_{w}^{i} F_{t, t+i} \frac{1}{\mu_{t+i}^{w}} N_{t+i \mid t}\left[W_{t}^{f l}-\left(1+\mu_{t+i}^{w}\right) M R S_{t+i \mid t} P_{t+i}\right],
$$

where $N_{t+i \mid t}=\left[\frac{W_{t}^{f l}}{W_{t+i}}\right]^{\frac{1+\mu_{t}^{w}}{\mu_{t}^{u}}} N_{t+i}$ and $M R S_{t+i \mid t}$ represent the average labour supply and marginal rate of substitution between consumption and leisure of a household, resetting the wage in period $t$, respectively. Consequently, the log-linearised optimal wage setting rule is given by

$$
w_{t}^{f l}=\mu_{t}^{w}+\left(1-\tilde{\beta} \theta_{w}\right) \sum_{i=0}^{\infty}\left(\tilde{\beta} \theta_{w}\right)^{i} E_{t}\left(\left[\frac{\mu^{w}}{\mu^{w}+\varphi\left(1+\mu^{w}\right)}\right] m w_{t+i \mid t}+w_{t+i}\right),
$$

where $m w_{t} \equiv m r s_{t}-\left(w_{t}-p_{t}\right)$ represents the inverse wage mark-up.

Following the assumptions for price setting, we define the domestic index for the wages newly set in period $t\left(\bar{W}_{t}^{n}\right)$ as a weighted average of the forward- and backward-looking prices, and assuming a rule of thumb for the backward-looking price-setters,

$$
W_{t}^{b l}=\bar{W}_{t-1}^{n}+\pi_{H, t-1}^{w}
$$


the following equations can be derived using some straightforward algebra:

$$
\begin{gathered}
W_{t}=\left[\theta_{w} W_{t-1}^{1-\theta_{w}}+\left(1-\theta_{w}\right)\left(\bar{W}_{t}^{n}\right)^{1-\theta_{w}}\right]^{\frac{1}{1-\theta_{p}}}, \\
\bar{W}_{t}^{n}=\left(1-\tau_{p}\right) W_{t}^{f l}+\tau_{p} W_{t}^{b l},
\end{gathered}
$$

where $\pi_{t}^{w}=\ln \left(\frac{W_{t}}{W_{t-1}}\right)$ represents the domestic wage inflation.

\section{A.1.3 International Risk Sharing and the UIP}

Before proceeding, we offer some helpful definitions and identities, which are related to the terms of trade and the exchange rate, and are used extensively in the following.

We start by defining different types of terms of trade relationships. The bilateral terms of trade between the domestic country and country $i$ represents the price of country $i$ 's goods in terms of domestic goods and is given by $S_{i, t}=P_{i, t} / P_{H, t}$. Thus the effective terms of trade is given by

$$
S_{t}=\frac{P_{F, t}}{P_{H, t}}=\left(\int_{0}^{1} S_{i, t}^{1-\zeta} d i\right)^{\frac{1}{1-\zeta}},
$$

which can be approximated by $s_{t} \equiv \log \left(S_{t}\right) \approx \int_{0}^{1} s_{i, t} d i$. Log-linearizing the domestic CPI under the assumption of a symmetric steady state satisfying the PPP yields

$$
p_{t}=p_{H, t}+\alpha s_{t} .
$$

Using the definition of the domestic PPI, there is a link to the domestic CPI:

$$
\pi_{t}=\pi_{H, t}+\alpha \triangle s_{t}
$$

We see that the gap between producer and consumer price inflation is proportional to the change in the terms of trade, depending on the openness of the country. ${ }^{14}$

Assuming that the LOOP holds on a brand level, we obtain $P_{i, t}(k)=\mathcal{E}_{t}^{i} P_{i, t}^{i}(k)$ $(\forall i, k \in[0,1])$, where $P_{i, t}^{i}(k)$ represents the price of good $k$ from country $i$ measured in terms of country $i$ 's currency. Integration over all products $k$ yields $P_{i, t}=\mathcal{E}_{t}^{i} P_{i, t}^{i}(\forall i, k \in[0,1])$, where $P_{i, t}^{i} \equiv\left[\int_{0}^{1} P_{i, t}^{i}(k)^{1-\varepsilon} d k\right]^{\frac{1}{1-\varepsilon}}$ represents the composite price index of goods from country $i$ measured in country $i$ 's currency. A log-linearization of $P_{F, t}$ around a symmetric steady state gives

$$
p_{F, t}=\int_{0}^{1}\left(e_{t}^{i}+p_{i, t}^{i}\right) d i=e_{t}+p_{t}^{*},
$$

\footnotetext{
${ }^{14}$ For $\alpha=0$ we obtain the closed economy version and consumer and producer prices coincide.
} 
where $p_{t}^{*}$ represents the log world price index and $e \equiv \log (\mathcal{E}) .{ }^{15}$ Using this with the definition of the terms of trade gives $s_{t}=e_{t}+p_{t}^{*}-p_{H, t}$. Since the foreign PPI measured in foreign currency units is given by $P_{F, t}^{*}=\left[\int_{0}^{1}\left(P_{i, t}^{i}\right)^{1-\zeta} d i\right]^{\frac{1}{1-\zeta}}$, the assumption of the LOOP on a brand level, combined with identical preferences and the assumption of no home bias yields the PPP:

$$
P_{F, t}=\mathcal{E}_{t} P_{F, t}^{*}, P_{H, t}=\mathcal{E}_{t} P_{H, t}^{*}, P_{t}=\mathcal{E}_{t} P_{t}^{*},
$$

where $P_{H, t}^{*}$ is defined in the same way as $P_{F, t}^{*}$ and represents the domestic PPI measured in foreign currency units.

Assuming complete securities markets gross returns across countries should be equal and first order conditions similar to those of the domestic country should hold in any country, leading to

$$
C_{t}=\varkappa_{i} C_{t}^{i} \mathcal{Q}_{i, t}, \forall t
$$

where $\mathcal{Q}_{i, t}=\frac{\mathcal{E}_{t}^{i} P_{t}^{i}}{P_{t}}$ represents effective bilateral real exchange rate and $\varkappa_{i}$ is a constant depending on initial conditions. Assuming (without loss of generality) symmetric initial conditions (implying zero net foreign assets) $\varkappa_{i}=\varkappa=1$. Taking logs and using the relationship between the terms of trade and the real exchange rate, we obtain

$$
c_{t}=c_{t}^{*}+(1-\alpha) s_{t}
$$

\section{A.1.4 Deriving Price and Wage Inflation}

Real marginal costs are defined as $m c_{t}=w_{t}-p_{H, t}-m p n_{t}$, where $m p n_{t}$ represents the marginal product of labour. Defining the real wage as $\omega_{t} \equiv w_{t}-p_{t}$, we derive

$$
m c_{t}=-\log \left(1-\alpha_{y}\right)+\omega_{t}+\alpha s_{t}+\frac{\alpha_{y}}{1-\alpha_{y}} y_{t}+\frac{1}{1-\alpha_{y}} a_{t} .
$$

A similar expression can be derived for the inverse wage mark-up:

$$
m w_{t}=\frac{\left(1-\alpha_{y}\right)+\Lambda \varphi}{\left(1-\alpha_{y}\right) \Lambda} y_{t}-\frac{\alpha \vartheta}{\Lambda} s_{t}-\frac{\alpha}{\Lambda} y_{t}^{*}-\Lambda^{-1} g_{t}-\frac{\varphi}{1-\alpha_{y}} a_{t}-\omega_{t} .
$$

Consequently, the corresponding natural values are represented by

$$
\begin{aligned}
m c_{t}^{n} & =-\log \left(1-\alpha_{y}\right)+\omega_{t}^{n}+\alpha s_{t}^{n}+\frac{\alpha_{y}}{1-\alpha_{y}} y_{t}^{n}+\frac{1}{1-\alpha_{y}} a_{t}, \\
m w_{t}^{n} & =\frac{\left(1-\alpha_{y}\right)+\Lambda \varphi}{\left(1-\alpha_{y}\right) \Lambda} y_{t}^{n}-\frac{\alpha \vartheta}{\Lambda} s_{t}^{n}-\frac{\alpha}{\Lambda} y_{t}^{*}-\Lambda^{-1} g_{t}-\frac{\varphi}{1-\alpha_{y}} a_{t}-\omega_{t}^{n},
\end{aligned}
$$

\footnotetext{
${ }^{15}$ Note that world $\mathrm{CPI}$ and $\mathrm{PPI}$ are the same as we assume that each country is of measure zero.
} 
where the natural terms of trade follow from (55) and (12)

$$
s_{t}^{n}=\sigma_{\alpha}\left[y_{t}^{n}-y_{t}^{*}-g_{t}\right]
$$

with $\sigma_{\alpha} \equiv \frac{1}{(1-\alpha) \Lambda+\alpha \vartheta}$, the natural real wage (under the absence of rigidities) equals the marginal product of labour,

$$
\omega_{t}^{n}=\log \left(1-\alpha_{y}\right)-\frac{\alpha_{y}}{1-\alpha_{y}} y_{t}^{n}+\frac{1}{1-\alpha_{y}} a_{t}-\alpha s_{t}^{n},
$$

and the natural level of output (in the absence of rigidities) is given by

$$
y_{t}^{n}=\alpha \Gamma y_{t}^{*}-\alpha(\Lambda-\vartheta) \Gamma s_{t}^{n}+\Gamma g_{t}+\frac{1+\varphi}{\left(1-\alpha_{y}\right)} \Gamma a_{t},
$$

where $\Gamma \equiv \frac{\left(1-\alpha_{y}\right)}{\left(1-\alpha_{y}\right)+\left(\varphi+\alpha_{y}\right) \Lambda}$. Note, that we implicitly assumed an optimal employment subsidy as in Galí (2003), so that $m w_{t}^{n}=m c_{t}^{n}=0$. Deviations of $m c_{t}$ and $m w_{t}$ from their "frictionless", flexible price levels are given by

$$
\begin{aligned}
\widehat{m c}_{t} & =\tilde{\omega}_{t}+\alpha \tilde{s}_{t}+\frac{\alpha_{y}}{1-\alpha_{y}} \tilde{y}_{t}, \\
\widehat{m w}_{t} & =\frac{\left(1-\alpha_{y}\right)+\Lambda \varphi}{\left(1-\alpha_{y}\right) \Lambda} \tilde{y}_{t}-\frac{\alpha \vartheta}{\Lambda} \tilde{s}_{t}-\tilde{\omega}_{t},
\end{aligned}
$$

where $\tilde{s}_{t} \equiv s_{t}-s_{t}^{n}=\sigma_{\alpha} \tilde{y}_{t}$.

Finally, log-linearizing the price-setting equations (42) - (44), and the corresponding wage-setting equations (49) - (51) yields

$$
\begin{aligned}
\pi_{H, t}^{p} & =\phi_{p}\left(\theta \tilde{\beta} E_{t} \pi_{H, t+1}^{p}+\tau_{p} \pi_{H, t-1}^{p}\right)+\kappa_{p} \tilde{y}_{t}+\lambda_{p} \tilde{\omega}_{t}+\alpha \lambda_{p} \tilde{s}_{t}+u_{t}^{p}, \\
\pi_{t}^{w} & =\phi_{w}\left(\theta \tilde{\beta} E_{t} \pi_{t+1}^{w}+\tau_{w} \pi_{t-1}^{w}\right)+\kappa_{w} \tilde{y}_{t}-\frac{\lambda_{w}}{\Lambda} h_{c} \tilde{y}_{t-1}-\lambda_{w} \tilde{\omega}_{t}-\frac{\alpha \vartheta}{\Lambda} \lambda_{w} \tilde{s}_{t}+u_{t}^{w},
\end{aligned}
$$

where

$$
\begin{aligned}
\lambda_{p} & \equiv \frac{\left(1-\tau_{p}\right)\left(1-\theta_{p}\right)\left(1-\tilde{\beta} \theta_{p}\right)\left(1-\alpha_{y}\right) \mu^{p}}{\mu_{p}+\alpha_{y}} \phi_{p}, \phi_{p} \equiv\left(\theta_{p}+\tau_{p}\left[1-\theta_{p}(1-\tilde{\beta})\right]\right)^{-1} \\
\lambda_{w} & \equiv \frac{\left(1-\tau_{w}\right)\left(1-\theta_{w}\right)\left(1-\tilde{\beta} \theta_{w}\right) \mu^{w}}{\mu^{w}+\varphi\left(1+\mu^{w}\right)} \phi_{w}, \phi_{w} \equiv\left(\theta_{w}+\tau_{w}\left[1-\theta_{w}(1-\tilde{\beta})\right]\right)^{-1} \\
\kappa_{p} & \equiv \frac{\alpha_{y}}{1-\alpha_{y}} \lambda_{p}, \kappa_{w} \equiv\left[\frac{\left(1-\alpha_{y}\right)+\Lambda \varphi}{\left(1-\alpha_{y}\right) \Lambda}\right] \lambda_{w},
\end{aligned}
$$

and $\varepsilon_{t}^{p}=\lambda_{p} \mu_{t}^{p}, \varepsilon_{t}^{w}=\lambda_{w} \mu_{t}^{w}$. Moreover, real wage gap dynamics are represented by

$$
\tilde{\omega}_{t}=\tilde{\omega}_{t-1}+\pi_{t}^{w}-\pi_{H, t}^{w}-\alpha \Delta s_{t}-\Delta \omega_{t}^{n}
$$




\section{A.2 About the Estimation}

Figure 5: Prior and Posterior Distributions

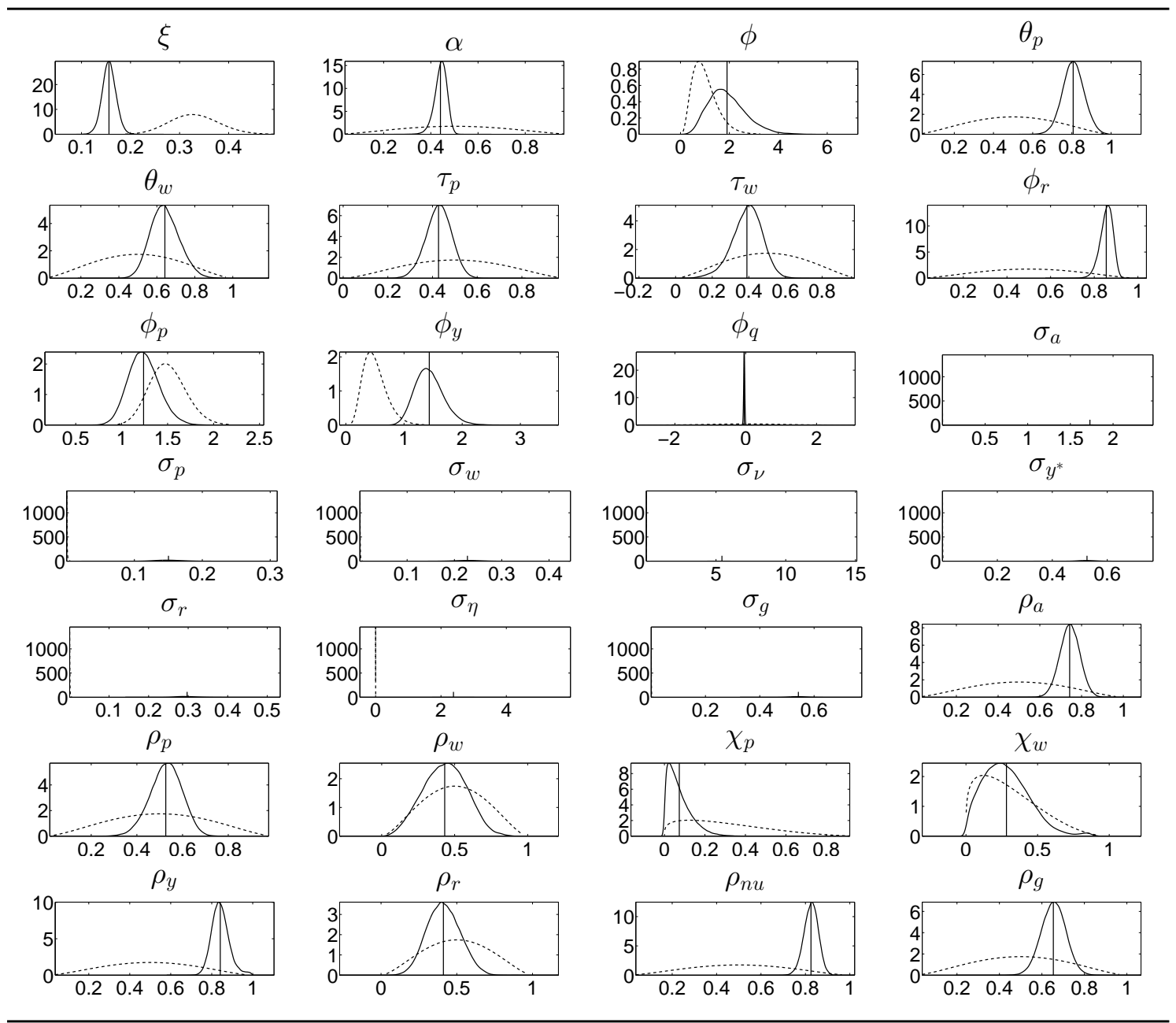

Dashed Line: Prior, Solid Line: Posterior, Vertical Line: Posterior Mean.

\section{Prior and Posterior Distributions}

\section{References}

Alpanda, S., K. Kotze, ANd G. Woglom (2010a): "Should Central Banks of Small Open Economies Respond to Exchange Rate Fluctuations? The Case of South Africa," Working Papers 174, Economic Research Southern Africa.

(2010b): "The Role Of The Exchange Rate In A New Keynesian Dsge Model For The South African Economy," South African Journal of Economics, 78, 170-191.

(2011): "Forecasting performance of an estimated DSGE model for the South African Economy," South African Journal of Economics, 79, 50-67. 
AN, S. AND F. SchorfHeide (2007): "Bayesian Analysis of DSGE Models," Econometric Reviews, 26, 113-172.

André, C., R. GuptA, AND P. T. Kanda (2012): "Do House Prices Impact Consumption and Interest Rate? Evidence from OECD Countries using an Agnostic Identification Procedure," Applied Economics Quarterly, 58, 19-70.

Apergis, N., B. D. Sim-Kengne, And R. GuptA (2014): "The Long-Run Relationship between Consumption, House Prices and Stock Prices in South Africa: Evidence from Provincial-Level Data," Journal of Real Estate Literature, 22, 8399.

Aron, J. AND J. Muellbauer (2013): "Wealth, Credit Conditions, and Consumption: Evidence from South Africa," Review of Income and Wealth, 59, 161-196.

AYE, G., R. GuPTA, AND M. MOdISE (forthcoming): "Do Stock Prices Impact Consumption and Interest Rate in South Africa? Evidence from a Time-Varying Vector Autoregressive Model," Journal of Emerging Market Finance.

Aye, G. C., R. Gupta, A. Kaninda, W. Nyakabawo, and A. Razak (2013): "House Price, Stock Price and Consumption in South Africa: A Structural VAR Approach," Corporate Ownership and Control, 10, 585-589.

Blanchard, O. J. (1985): "Debt, Deficits, and Finite Horizons," Journal of Political Economy, 93, 223-247.

Blinder, A. S. AND R. M. Solow (1973): "Does fiscal policy matter?" Journal of Public Economics, 2, 319-337.

Bonga-BongA, L. (2011): "Equity Prices And Inflation In South Africa: An Empirical Analysis," Journal of applied Business Research, 27, 105-112.

(2012): "Equity Prices, Monetary Policy, And Economic Activities In Emerging Market Economies: The Case Of South Africa," Journal of applied Business Research, 28, 1217-1228.

Burger, P. (2010): "The South African business cycle: what has changed?" South African Journal of Economic and Management Sciences, 13, 26-49.

Calvo, G. (1983): "Staggered Prices in Utility-Maximizing Framework," Journal of Monetary Economics, 12, 983-998.

CASTELnuovo, E. AND S. Nisticó (2010): "Stock market conditions and monetary policy in a DSGE model for the U.S," Journal of Economic Dynamics and Control, 34, 1700-1731. 
DAS, S., R. GuptA, And P. T. KandA (2011): "Bubbles in South African House Prices and their Impact on Consumption," Journal of Real Estate Literature, 19, 69-91.

Dixit, A. K. AND J. E. Stiglitz (1977): "Monopolistic Competition and Optimum Product Diversity," American Economic Review, 67, 297-308.

Finocchiaro, D. AND V. Q. Heideken (2013): "Do Central Banks React to House Prices?" Journal of Money, Credit and Banking, 45, 1659-1683.

Funke, M., M. PAetz, ANd E. Pytlarczyk (2011): "Stock market wealth effects in an estimated DSGE model for Hong Kong," Economic Modelling, 28, 316334.

Galí, J. (2003): "New Perspectives on Monetary Policy, Inflation, and the Business Cycle," in Advances in Economic Theory, Vol. III, ed. by M. Dewatripont, L. Hansen, and S. Turnovsky, Cambridge, University Press, 151-197.

Galí, J. AND T. Monacelli (2005): "Monetary Policy and Exchange Rate Volatility in a Small Open Economy," Review of Economic Studies, 72, 707-734.

Gupta, R. AND R. SteINBACH (2013): "A DSGE-VAR model for forecasting key South African macroeconomic variables," Economic Modelling, 33, 19-33.

LUCAS, R. J. (1976): "Econometric policy evaluation: A critique," CarnegieRochester Conference Series on Public Policy, 1, 19-46.

MoOLMAN, E. (2004): "A Markov switching regime model of the South African business cycle," Economic Modelling, 21, 631-646.

MoOlman, E. AND J. JoRdAan (2005): "Can Leading Business Cycle Indicators Predict The Direction Of The South African Commercial Share Price Index?" South African Journal of Economics, 73, 68-78.

MuRoyiWA, B. (2011): "Identifying the interdependence between South Africa's Monetary Policy and the Stock Market," Masters dissertation, Department Of Economics and Economic History Rhodes University, Grahamstown.

ODHIAMBO, N. (2010): "Stock market development and economic growth in South Africa: An ARDL-Bounds," Tech. rep., Department of Economics, University of South Africa.

PARiÉs, M. D. AND A. NotARPietro (2008): "Monetary policy and housing prices in an estimated DSGE model for the US and the euro area," European Central Bank Working Paper Series.

Smets, F. AND R. Wouters (2007): "Shocks and Frictions in US Business Cycles: A Bayesian DSGE Approach," American Economic Review, 97, 586-606. 